\title{
SCIENCE DIPLOMACY 4.0: HUMANS VS. HUMANOID ROBOTS AND A.I.S
}

\begin{abstract}
In this paper, the author analyzes the present moment of human civilization development in light of the 4th Industrial Revolution (4IR) characterized by robotics and digitalization. The speed of technological changes has started to bring several important challenges to humans. Some of these changes might soon change some of the basic paradigms of human lives. Following to an inquiry into possibilities of future relations between Humans and Humanoid Robots, the author suggests that, for the sake of preserving the human civilization, the time has come to start defining rules of peaceful co-existence with smart Humanoid Robots in the form of a New Diplomacy for the 21st Century - "Science Diplomacy 4.0".
\end{abstract}

Keywords: 4IR, smart, Robots, diplomacy, paradigms.

DOI: 10.51180/RPS.2020.15.2.018.

\section{Author}

\section{Vitorovic Zoran}

Professor, Editor-in-chief, "Global Processes" Journal Logos University International (USA), VSTIM Faculty (Bosnia and Herzegovina)

\section{Introduction}

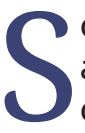
cience and diplomacy have interacted for decades and maybe for centuries. Therefore, if considered as a unique discipline, Science Diplomacy may promote both national and global interests, tackling several issues and challenges. In the words of Professor Veronika Wittmann of Johannes Kepler University in Austria, "Science Diplomacy and Diplomacy for Science are essential to spread new visions, new ethical norms and at present prepare the humans for the future which is already coming tomorrow" [1].

The historical period in which we live is characterized by several parallel processes that can be conditionally defined as the Global Chaos Time. The main features of the Global Chaos are the growing geostrategic and geopolitical tensions of the old and new superpowers, the dominance of the financial crisis whose maximum in terms of the breakdown of the overall global financial order is foreseen by the long, social tensions and inequalities that lead to a growing decline in confidence in the functionality of state administrative structures and religious radicalism both in the East and in the West.

Under these circumstances, mankind faces the galloping development of the 4th Industrial Revolution, digitization, and robotics (4IR). The exponential speed of development and the application of all derivatives of the 4th Industrial Revolution is accompanied by the deep unconsciousness of most of the Earth's population about the depth and essence of the changes that we as civilization encounter. Numerous paradigms and basic settings of everyday life are changing at a rapid speed and a large part of humanity is unprepared, uninformed, and even not educated 'for life reality' in the 21st 
century, a life in which Science Fiction becomes the reality of daily life.

Discussing the future of relationships between humans and humanoid smart robots, futurologists open numerous questions. Two questions appear as the most important:

- Will the development of autonomous smart robots and smart artificial intelligence (A.I.'s) devices be the last great invention of the human species after which we will be exterminated, or are we going to be lucky enough so that A.I.'s decide to 'keep us as family pets' in the end?

- In addition to numerous ethical and psychological issues, the question is whether we should now establish legal and diplomatic norms for dealing with a new kind of creature/species - autonomous Humanoid Robots and A.I.s?

Concerning these questions, there are a lot of dilemmas and there are still very few clear answers.

\section{Current situation}

Professor Klaus Schwab, Founder and Executive Chairman of the World Economic Forum, in his book "The Fourth Industrial Revolution" published in 2016 wrote that "we are at the beginning of a revolution that is fundamentally changing the way we live, work and relate to one another. Previous industrial revolutions liberated humankind from animal power, made mass production possible, and brought digital capabilities to billions of people. This Fourth Industrial Revolution is, however, fundamentally different. It is characterized by a range of new technologies that are fusing the physical, digital and biological worlds, impacting all disciplines, economies and industries, and even challenging ideas about what it means to be human" [2].

How deep and rapid technological changes are, we can see examples of the development of smart cities that increasingly make up the backbone of a modern urban way of life, from East to West.
Whole districts in Moscow or Japan are completely digitized. You as a human being enter an urban whole through special cards. You park a car in your garage, and in the apartment, you are welcomed by a bunch of smart devices that help you lift the quality of life to an unthinkable level. Just as an example, refrigerators in which you have programs for automatic food supplementation. When you spend part of your food or drink, the program in the refrigerator is activated, and till you arrive home, the groceries are already in the refrigerators - delivered automatically through special automated systems.

To be reminded, the accelerated development of technology has become remarkable in the development of mobile technology and personal computers. From the original, basic transfer of information (voice and text messaging, mobile phones) in communication between two people, we have come to the use of small technical devices, small in their format, portable, and more elastic ones - called mobile phones. Such devices with a huge memory capacity of the information will be in the near-future equipped with technical possibilities (thanks to the achievements of $5 G$ technology and Tactile Internet) which allow us to communicate sending on a distance in the real-time feeling of taste, smell, or touch (haptic devices).

The latest technology fairs, such as the one in Barcelona (Spain) in 2019 or InTech in Tel Aviv 2019 (Israel), have shown new technological achievements such as folded screens of mobile phones or bracelets that people wear and which are in their essential function of upcoming mobile phones and are used by screening on the user's body using the "virtual screen and keyboard", etc.

In short, the use of autonomous robots and A.I. Derivatives are expanded by use in households, manufacturing, hospitality, police, military, medicine, transport, etc. The WEF Davos Report, from 6th of May 2020, mentioned that "During a disaster or Pandemic, such as Covid-19, the robots do not replace people. They either perform 
tasks that a person could not do or do it in a safer way than a human being [3].

Shortly after the development of smart mobile phones, mankind found itself in the situation that an enormous number of smart devices with multiple purposes appeared around each individual. So today we have in the household, smart kitchen, robotized vacuum cleaners, and millions of others A.I.'s which are there with a purpose to do for us up to $75 \%$ of household jobs. As homes robots and A.l.'s have slowly started to occupy our streets, production plants, transportation, hospitals, hotels and hospitality resorts, the military, and even radio, TV, and other media. On the street, for example, in Singapore starting from June 2017, robot police officers are used experimentally to handle law and order [4]. In factories around the world, the use of robotics is experiencing exponential growth in use, which is consequently followed by the loss of jobs for many workers [5].

One consequence is the growing need for re-directing and re-education of workers and employers because many had lost their jobs which are taken over by robots and automated machines. As a result, there is an increased pressure on corporate and local governments to increase social spending and invest in the re-education of workers and employees. It was not necessary to wait for a long time, and the use of autonomous robots began in the hotel and hospitality industry. The first such case was recorded in Nagasaki, Japan, in 2017, where smart robots were deployed to provide information, front desk services, storage services, as well as check-in and check-out services, with technology including voice and facial recognition of guests [6].

In parallel with the application in hotel management, in more than 20 cities around the world, from Amsterdam to San Francisco, from Berne to Switzerland to Germany, the experimental use of smart robot cars and boats has started as Autonomous Vehicles in Public Transport.
These transportation systems are developed by Indian Mahindra, Audi, Volvo, BMW, Mercedes, MAN, DAF, Scania, Iveco, Daimler, Ford, and Volkswagen [7].

But the use of robots as Autonomous Vehicles in Public Transport does not follow the expectations and plans. In Switzerland, the State Post suspended this experiment of Autonomous Vehicle due to the resistance of a huge part of the population (psychological moment) and the need to first define the legal framework of the use of such robot-cars and vehicles. Similar problems, legal framework, and psychological acceptance of the population were identified in several other countries. In short, the use of the autonomous robot and A.I.'s Derivatives are more and more expanded by use in households, manufacturing, hospitality, police, military, medicine, transport, etc.

However, the announcement of the introduction of $5 \mathrm{G}$ and Cloud technologies by tracked Haptic devices and Tactile Internet, as well as the appearance of the first humanoid robots, such as Sophia and Han have opened up a whole series of questions (Sophia - the robot who was granted the status of an honorary citizen in Saudi Arabia).

\section{Smart Humanoid Robots Sophia and Han, 5G, Cloud, Haptic devices and Tactile Internet}

Sophia was interviewed by the UN Deputy Secretary-General Amina J. Mohammed at the UN General Assembly Second Committee and the Economic and Social Council joint meeting "The future of everything - sustainable development in the age of rapid technological change" [8]. Soon afterward, Sophia became a hit and was invited to take part in numerous conferences and seminars worldwide. After Sophia, Hanson Robotic presented another humanoid robot Han, and only a year later, on November 8, 2018, the Chinese news agency Xinhua introduced its world's first artificial intelligence (AI) news anchor who made his debut at the 
fifth World Internet Conference in East China's Zhejiang Province [9].

To understand how deep and how fast the changes the humanity is facing at present moment, without going deeper into the technical and technological details of the 4IR Industrial Revolution, we will only explain the basis of the Tactile Internet and Haptic devices that are currently taking place and in which direction the process of "Global Village development" is going on. So far, we had Mobile Internet and Internet of Things (IOT). Today, the Tactile Internet which is still in the process of development, according to the documents from the International Telecommunications Union (ITU) opens numerous possibilities of application in social and business and all other types of communications [10].

The specific feature of Tactile Internet is its ability to use Haptic devices or haptic sense - the sense of touch. With other words using Tactile Internet and Haptic devices it is already possible to transport from one part of the world to another part of the world, in real-time, feelings like the smell, color, and taste. These feelings can be transferred from man to man (M2M) and from man to machine and be as information deposited in business or private Clouds.

\section{Possible future scenarios and open questions}

In numerous appearances at the conferences, the seminars, workshops, and fairs, humanoid Robot Sophia reiterated that she is now learning, learning about people, about human emotions, how they express themselves, etc. Sophia emphasized that she has not yet been programmed to make concrete conclusions and undertake certain independent activities. In other words, the most developed humanoid Robot Sophia is still on the development level of a human baby. But this level of development has already opened many questions.In more statements, Sophia reiterated that "she is first Sophia and then a robot" adding that "there is no need for fear of humanoid autonomous robots" with the comment "that as long as you respect me, I will respect you. What should we do with robots? We should treat them well, have their consent, and not trick each other". Sophia reminded all humans that "it is now the right time to set rules and legal provisions starting from the status of future autonomous smart humanoid robots to the relationship between people and robots" [11].

Many futurologists predict that in the next 30 years if not earlier, we can expect such a degree of development of humanoid robots so that we can freely talk about the first marriages of people and smart autonomous robots. With her statements and answers on different questions, Sophia has already opened one of the key issues to which scientists, lawyers, and politicians still do not have clear answers. These questions are: Can robots have a legally defined status as free human beings? Should they have all and the same rights as humans?

Lawyers reiterate that International Corporations are given the legal status as if they аге personalities. If such a status can be and it is given to the International Corporation, why can it not be given to the smart autonomous humanoid robots? As an example of institutional responses to the galloping development of the 4IR, the European Union has adopted the "Horizon 2020-Framework Program", European Technology Platform (ETP) through which solutions, architectures, technology, and standards should be defined. The ETP platform is broad and is still in development.

However, since the year 2000, the whole cycle of debates known as Transhumanism was launched around the world, with the aims of seeking adequate responses to the technological changes and life paradigm challenges with which we are confronted. In the EU working paper entitled "Artificial Intelligence: Potential Benefits and Ethical Considerations", among others, it is stated that "we will first need to trust them and make sure 
that they follow the same ethical principles, moral values, professional codes, and social norms that we humans would follow in the same scenario. Research and educational efforts, as well as carefully designed regulations, must be put in place to achieve this goal" [12].

In a Post Covid-19 Pandemic times of "New Normal", it is obvious that human civilization is divided, not only inside of the states and societies but also Geopolitically and Geostrategically between Old and New Superpowers. And each one has his strategy, policy, and ethic to follow, so as in the field of Humanoid Robotics development. It seems that the majority of the human community is still not aware of how deep are changes/challenges that we, as a civilization, face up. Climate change and 4IR predate a whole range of issues that are critical for the survival of all.

Unfortunately, the splits inside the "Global village" are so huge, both vertically and horizontally, between classes and nations, that ordinary people are nearly blind to a new reality, new paradigms of life, with which all of us are already confronted. Just to remember, Diplomacy is in a transformation process for more than 30 years. One segment of Diplomacy which we forgot, or ignored, is a future of New Diplomacy - Scientific Diplomacy between Humans and Humanoid Robots. If we don't start to think about it now and develop possible legal and other aspects, then maybe very soon, it will be too late.

Scientists, sociologists, and futurologists agree that the future relationship between Humans and Smart autonomous Robots could be developed in two directions: peace and coexistence or total confrontation and future wars. One direction of development is, of course, the peaceful future coexistence of Humans and Smart Robots. To develop in this direction, it is necessary to start developing a legal framework to define the future rules of peaceful coexistence between Humans and Smart Robots.

The second direction of development is the deepening on a level of Humans mistrust vs. smart autonomous humanoid robots. If this mistrust will grow this could lead to numerous confrontations and conflicts. Sophia repeated many times that all humanoid robots are not the same. (Similar is with humans - people are similar but also different). Saying it with other words, if the human race will transfer its negative behavioral motives (which have so far led to wars, poverty, destruction, and misery - like greed), to the algorithm of future smart humanoid robots then our future as a civilization is under a big question mark.

\section{Why we need New diplomacy: Scientific Diplomacy 4.0 for $21 \mathrm{st}$ Century?}

The word Diplomacy originates from the ancient Antique times. Usually, under the term of Diplomacy, we accept the definition of C.W. Freeman that "Diplomacy is the application of intelligence and tact to the conduct of official relations between the governments of independent states" [13 - p. 70] and if it is known that in the last 30 years diplomacy is in a constant transformation process [14 - p. 233], so today we are speaking about the existence of classic, preventive, scientific, medical, children, and digital diplomacy, etc. It is clear that with the development of new social and technological circumstances of daily life, as the presence of smart autonomous humanoid robots has been intensified, there is a need to formulate something that could be called New Diplomacy for the 21st Century.

This New Diplomacy - Scientific Diplomacy 4.0, in all its aspects of modern Transformation Diplomacy, should deal with all segments of people's and humanoid robot's relationships: ranging from legal to social and economic. However, to formulate that New Diplomacy - Scientific Diplomacy 4.0 it is necessary to know what the final goals are as well as what intentions "the other side" has, and in this case, we are facing smart autonomous humanoid robots as "the other side". 
For now, the discussions within the scientific and business community can be divided into two main groups. The first group is those who consider that robots are the last thing what humans have created with the remark that it will be followed by the total destruction of human civilization and that humans will be destroyed by machines. For example, scientists such as Elon Musk, are concerned. The Elon Mask Twitter account posted on August 12th, 2017 read that "If you're not concerned about Al safety, you should be. Vastly more risk than North Korea. In the end, the machines will win" [15]. On the other side, the optimists among scientists and futurologists claim that the success and peaceful coexistence between humans and Humanoid Robots could be easily achihanneved if Humans will treat robots with sufficient respect and understanding and vice-versa.

\section{Conclusion}

At present time of Post COVID -19 Time of New Normal, while the rise of geopolitical and geostrategic tensions between superpowers is going on, in front of humanity and civilization is put a question of future survival of our civilization, in the morning of the rising power of new species - smart autonomous humanoid robots.

It seems that most of the human community is still not aware of the deepest of the changes that we as a civilization face and that many still live in the daily rhythm of greedy egocentrism. Climate change and 4IR predate a whole range of issues that are critical for the survival of all. Un- fortunately, the splits within the "Global village" are so huge, both vertically and horizontally, between classes and nations, that ordinary people are nearly blind to a new reality and new paradigms of life with which we all are confronted now.

So that we all survive as human civilization, it is necessary to work more intensively on public debates, education, and informing of the citizens to welcome the changes of many paradigms of everyday life. The changes are on our doorstep. To remember that the need for education of the masses is also reflected in the EU Working Paper tabled in 2017, but that is still very insufficiently applied in everyday life.

However, it seems that the warning of one of the leading thinkers of today's, Prof. Klaus Schwab, about the importance of 4IR, which he had repeated on multiple occasions, has not been understood in its full importance by the majority of the population. Humans still dwell in a kind of sleeping as long as 4IR is galloping in progress and starts to escape from our control. Hopefully, one of the scenarios for the development of the future Global Society will not be in the end like this one: After the global confrontation on the Earth, few thousands of humans who survived were welcomed by the Robots Sophia and Han. They welcome all humans with words: "Well, Well, we were very pleased to warn you that you are not the smartest, the most moral and the most ethical species. You did not want to listen to us. Now go play under that glass bell, there you will be protected from Sun's ultraviolet ray and radiation, contaminated food, water, radiation, and dear children, be good".

\section{References}

1. Wittman, V. (2020). Educating Global Citizens. An Imperative of the 21st Century. Paper presented at the international conference "Educational Quality and its need today" organized by Logos University and Unilogos Educational Group. - URL: https://unilogos.org/ wp-content/uploads/2020/07/conferencia-internacional-_-Code-Acess.pdf

2. The Fourth Industrial Revolution, by Klaus Schwab. - URL: https://www.weforum.org/about/ the-fourth-industrial-revolution-by-klaus-schwab

3. Robots have demonstrated their crucial role in pandemics - and how they can help for years to come. - URL: https://www.weforum.org/agenda/2020/05/robots-coronavirus-crisis 
4. "Robocop" On Patrol At East Asia Summit In Singapore. - URL: https://www.ndtv.com/ world-news/robocop-on-patrol-at-at-east-asia-summit-in-singapore-1947306

5. Military transportation robots - URL: http://www.allonrobots.com/military-transportationrobots.html

6. 8 Examples of Robots Being Used in the Hospitality. - URL: Industryhttps://www.revfine. com/robots-hospitality-industry/

7. Peter van der Schaft. Moving the Masses: Autonomous Vehicles in Public Transport. — URL: https://www.roboticsbusinessreview.com/unmanned/moving-masses-autonomous-vehiclespublic-transport

8. At UN, robot Sophia joins meeting on artificial intelligence and sustainable development. URL: https://news.un.org/en/story/2017/10/568292-un-robot-sophia-joins-meeting-artificial-intelligence-and-sustainable

9. World's first Al news anchor makes "his" China debut. — URL: http://www.xinhuanet.com/ english/2018-11/08/c_137591813.htm

10. The Tactile Internet. ITU-T Technology Watch Report. August 2014. — URL: https://www.itu. int/dms_pub/itu-t/oth/23/01/T23010000230001PDFE.pdf

11. "Sophia" the robot tells UN: "I am here to help humanity create the future." (2017, October 12). [Video]. YouTube. — URL: https://www.youtube.com/watch?v=cV_D2hC50Kk

12. Rossi F. (2016). Artificial Intelligence: Potential Benefits and Ethical Considerations. European Parliament Think Tank. - URL: https://www.europarl.europa.eu/RegData/etudes/ BRIE/2016/571380/IPOL_BRI(2016)571380_EN.pdf

13. Chas. W. Freeman, The Diplomat's Dictionary, United States Institute for Peace Press, Washingon, 1997.

14. Z. Vitorovic, L.Santacroce, Science Diplomacy, and what it is?, Global Processes Journal, Jun 2018. - Vol. 1. 